\title{
OPTIMIZATION OF REBAUDIOSIDE A EXTRACTION FROM STEVIA REBAUDIANA (BERTONI) AND QUANTIFICATION BY HIGH PERFOMANCE LIQUID CHROMATOGRAPHY ANALYSIS
}

\author{
ASRUL AFANDI*, SHAZANI SARIJAN AND RANAJIT KUMAR SHAHA \\ Faculty of Agro Based Industry, Universiti Malaysia Kelantan, Jeli Campus, Locked Bag No. 100, 17600 \\ Jeli, Kelantan, Malaysia.
}

Corresponding author: seroskg@gmail.com

\begin{abstract}
A solid-liquid extraction and an HPLC method for determination of rebaudioside A from the leave parts of Stevia rebaudiana were developed. Separation method consisted of solvent extraction of leaf powder using various solvents like petroleum ether, methanol, diethyl ether and butanol followed by its purification using high performance liquid chromatography in order to obtain bioactive compound rebaudioside A. This solvent selection is very important prior to alternative extraction methods since it can be used as a pre-extraction solvents, main solvents, or co-solvents. The problem of hydrolysable components and solvent removal difficulties in the conventional extraction led us to study further the effects of solvent properties on the conventional extraction using Soxhlet method in order to determine the best solvent or solvent mixture for high extraction yield of $S$. rebaudiana. The chromatographic separation was realized using a C18 column, mobile phase consisting of methanol: water with UV detection at $210 \mathrm{~nm}$. Based on the yield of extraction and glycosides content, methanol was found to be best solvent.
\end{abstract}

KEYWORDS: Stevioside, HPLC, methanol, Stevia rebaudiana

\section{Introduction}

The food industry traditionally used sugar as the sweetening agent. However, there is increasing demand for other sweeteners partially in response to consumer preference (Leung and Foster, 1996). Additionally the sweetener should fulfill the requirements relating to non-toxic nature, sugar-like taste profile, low calorific value, heat and $\mathrm{pH}$ stability. In recent years, there has been considerable interest in Stevia-based natural source sweeteners that possess many desired qualities (Leung and Foster, 1996).

Stevia, botanically known as Stevia rebaudiana (Bertoni) (Family- Asteraceae) is a sweet herb. Stevia is a member of the daisy family (Lewis, 1992). S. rebaudiana (Bertoni) is one of 154 members of the genus stevia and one of only two that produce sweet steviol glycosides (Soejarto et al., 1982). The leaves are mid green and intensely sweet. The plant bears greenish cream flowers in autumn. Typically, it has a mild licorice like taste and is completely natural in its biochemical profile (Leung and Foster, 1996). The sweet principle was first isolated in 1909 and only in 1931 was the extract purified to produce stevioside, the chemical structure of which was established in 1952 as a diterpene glycoside. The leaves are found to contain a complex mixture of eight sweet diterpene glycosides, including stevioside, steviolbioside, rebaudiosides 


\section{Optimization of Rebaudioside a Extraction from Stevia Rebaudiana (Bertoni) and Quantification by High}

Perfomance Liquid Chromatography Analysis

(A,B,C,D,E) and dulcoside A. Rebaudioside A is the sweetest and the most stable, and it is less bitter than stevioside. Rebaudioside $\mathrm{E}$ is as sweet as stevioside, and rebaudioside $\mathrm{D}$ is as sweet as rebaudioside A, while the other glycosides are less sweet than stevioside (Cramer and Ikan, 1987).

The stevia leaves are extracted with hot water or alcohols. In some cases, the leaves are pre-treated with non polar solvents such as chloroform or hexane to remove the essential oils, lipids, chlorophyll and other non polar substances. The extract is clarified by precipitation with salt or alkaline solutions (Midmore and Rank, 2006). The extract is concentrated and redissolved in methanol for crystallization of the glycosides. The crystals are formed almost by pure stevioside.

In many cases, it is difficult to find quickly suitable experimental conditions for a given separation task. Prediction of separation conditions is not yet straightforward. Therefore, good experimental design becomes increasingly important. Orthogonal design which only focuses on the main effects of the factors, allows the number of experiments to be drastically reduced. In separation science, this kind of experimental design has already shown its usefulness in liquid chromatography and capillary electophoresis (Hu et al., 2002).

In this study, the optimal conditions to extract rebaudioside A from the leaves of $S$. rebaudiana were investigated systematically in order to explore a proper process to optimize the yield of rebaudioside A. The study also was conducted to examine the technological process on the production of natural sweeteners rebaudioside A from the local $S$. rebaudiana. There is a need of modifying this process to reduce the consumption of chemicals and waste streams.

\section{Materials and methods}

\section{Plant material/sample}

Fresh mature leaves from 2 years healthy old plants of Stevia rebaudiana were collected from Malaysian Agricultural Research and Development Institute (MARDI), Bachok, Kelantan, Malaysia. The samples were from the MS007 and MS012 varieties originated from Canada.

\section{Preparation of Stevia leaves}

Fresh mature leaves from 2 years healthy old plants of Stevia rebaudiana were harvested by cutting the plant at $5-10 \mathrm{~cm}$ from upper parts. The brown and yellow leaves were removed from the plants then, washed in clean water and spread on trays covered with cheese-cloth to remove excess water. The leaves were also dried in direct sunlight at temperature ranged from $25^{\circ} \mathrm{C}$ to $30^{\circ} \mathrm{C}$ for 24 hour to 48 hour. The sample materials were blended to powder form with a highspeed blender (Braun KMM 30 mill, type 3045, Germany). This was kept in a sealed polyethylene bags and stored at $4 \pm 1^{\circ} \mathrm{C}$ in a refrigerator until used (Abou-Arab, 2010).

\section{Rebaudioside A extraction process}

The grounded fine powder was used for the extraction of rebaudioside A. An amount of $5 \mathrm{gm}$ of dried leaf powder was extracted with $50 \mathrm{ml}$ hot methanol using soxhlet apparatus for 2 hours. The extract was filtered using filter paper (Whatmann No. 1) and the residue was re-extracted two times with methanol. The filtrate was further concentrated in rotary flash evaporator at $60^{\circ} \mathrm{C}$ and an amount of $50 \mathrm{ml}$ of distilled water was added to dissolve the crude extract. The extract was Journal of Tropical Resources and Sustainable Science. Volume 1 (1):62-70 


\section{Optimization of Rebaudioside a Extraction from Stevia Rebaudiana (Bertoni) and Quantification by High Perfomance Liquid Chromatography Analysis}

further separated by using 500ml separatory funnel (Sigma Aldrich) with $25 \mathrm{ml}$ of diethyl ether as a reagent to remove the green colour. Lower transparent layer was collected and extracted again with Butanol. Finally the butanol extract (upper layer) was collected and refrigerated overnight at $4^{\circ} \mathrm{C}$ to get fine crystals (Harmanjit, 2011).

The main factors that affect the extraction of rebaudioside A such as temperature, extraction time, materials ratio (weight of the leaves: volume of the extracting agent), where the extracting agent, for instance, $100 \%, 75 \%, 50 \%$ solvent and the number of extraction were manipulated individually to determine the optimum extraction condition.

\section{High Performance Liquid Chromatography Analysis (HPLC)}

HPLC analyses were carried out using Nuclosil $100 \mathrm{C} 18(25 \mathrm{~cm} \times 4.6 \mathrm{~mm}$ I.D., $5 \mu \mathrm{m})$. The column temperature was maintained at $27-28^{\circ} \mathrm{C}$ and $\mathrm{UV}$ detection was adjusted at $210 \mathrm{~nm}$. Mobile phase was HPLC grade acetonitrile and water (80:20) and the $\mathrm{pH}$ adjusted to 3.0 with phosphoric acid ( $85 \%$ reagent grade). The samples were filtered through $0.22 \mu \mathrm{m}$ millipore filter or equivalent. The injection volume was set to $10 \mu \mathrm{L}$ at a flow rate of $1 \mathrm{ml} / \mathrm{min}$. The standard stevioside (>99.3\% purity) and rebaudioside A (>97\% purity) (Wako pure Chemical Industries, Ltd. Japan) were used. An amount of $50 \mathrm{mg}$ of dried $\left(105^{\circ} \mathrm{C}, 3\right.$ hour) stevioside or rebaudioside A standard were diluted with $100 \mathrm{ml}$ mobile phase and re-diluted to $1 \mathrm{mg} / \mathrm{ml}$ by serial dilution.

HPLC (Shimadzu) column was equilibrated by pumping mobile phase through it until a drift-free baseline was obtained. The chromatograms of the sample solution and of the standard solution were recorded in 10 minutes. The chromatograms of each sample were compared to the standard to find the retention time of rebaudioside A. The peak areas of rebaudioside A were calculated automatically by solutions software equipped with HPLC. The percentage of rebaudioside A content was calculated using the formula as follows:

$$
\begin{aligned}
& \% \text { stevioside }=[\mathrm{Ws} / \mathrm{W}] \times[\mathrm{Aa} / \mathrm{As}] \times 100 \\
& \% \text { rebaudioside } \mathrm{A}=[\mathrm{Ws} / \mathrm{W}] \times \mathrm{Ac} \times[1.20 / \mathrm{As}] \times 100
\end{aligned}
$$

Where,

Ws = weight $(\mathrm{mg})$ of stevioside in the standard solution, $\mathrm{W}=$ weight of sample $(\mathrm{mg})$, As $=$ Peak area of stevioside from the standard solution, $A c=$ Peak area of rebaudioside A from the sample solution and $1.20=$ molecular weight relative of rebaudioside $\mathrm{A} /$ molecular weight of stevioside.

\section{Results and discussion}

High performance liquid chromatography, being more sensitive and accurate, was used for the estimation of rebaudioside A content in the samples. The identification and quantification of rebaudioside A content in the extracted samples was done by comparing the retention time and peak area of sample with that of the standard. The retention time $\left(R_{t}\right)$ of stevioside in standard $\left(0.1 \mathrm{mg} / \mathrm{ml}\right.$ and $1 \mathrm{mg} / \mathrm{ml}$ ) was found to be $3.3 \mathrm{~min}$ (Figure $1 \mathrm{a}$ ) and $\mathrm{R}_{\mathrm{t}}$ of rebaudioside $\mathrm{A}$ is 4.1 min (Figure 1b). Figure 2 shows the comparison of rebaudioside A content at different material ratio indicating higher content of rebaudioside $A$ by extraction at material ratio 1:10. (Peak area at $4.1 \mathrm{~min})$. 
(a)

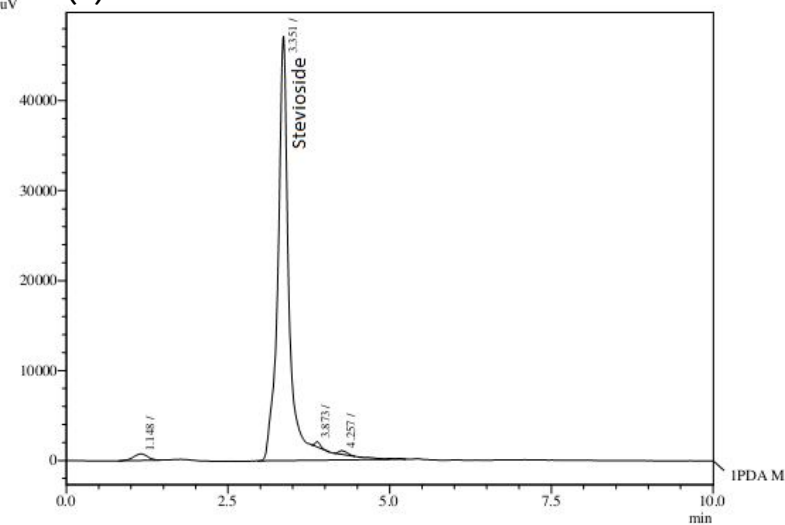

(b)

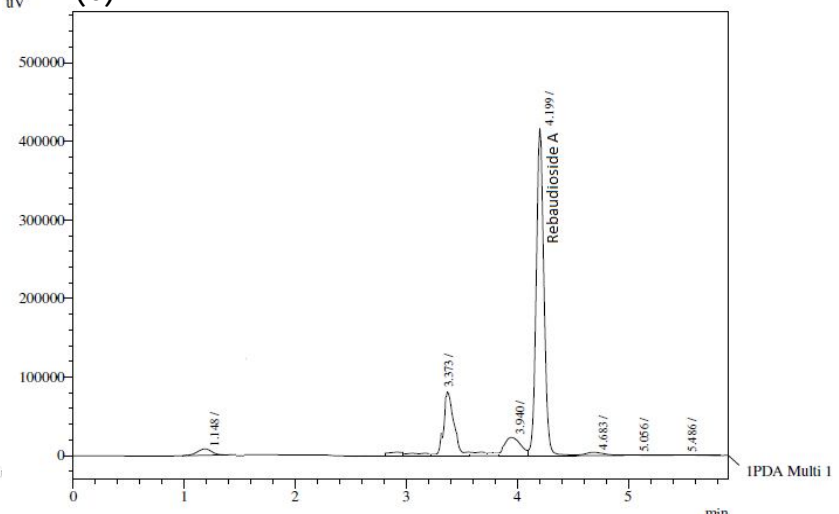

Figure 1: HPLC Chromatogram of (a) stevioside and (b) rebaudioside A from standard solution, Rt of stevioside was $3.3 \mathrm{~min}$ and rebaudioside A was 4.1 min under separation acetonitrile:water $(80: 20 \mathrm{v} / \mathrm{v})$ as the elusion solvent at flow rate of $1 \mathrm{ml} / \mathrm{min}$ and the detection wavelength $245 \mathrm{~nm}$, column was Nuclosil $100 \mathrm{C} 18(25 \mathrm{~cm} \times 4.6 \mathrm{~mm}$ I.D., $5 \mu \mathrm{m})$.

(a)
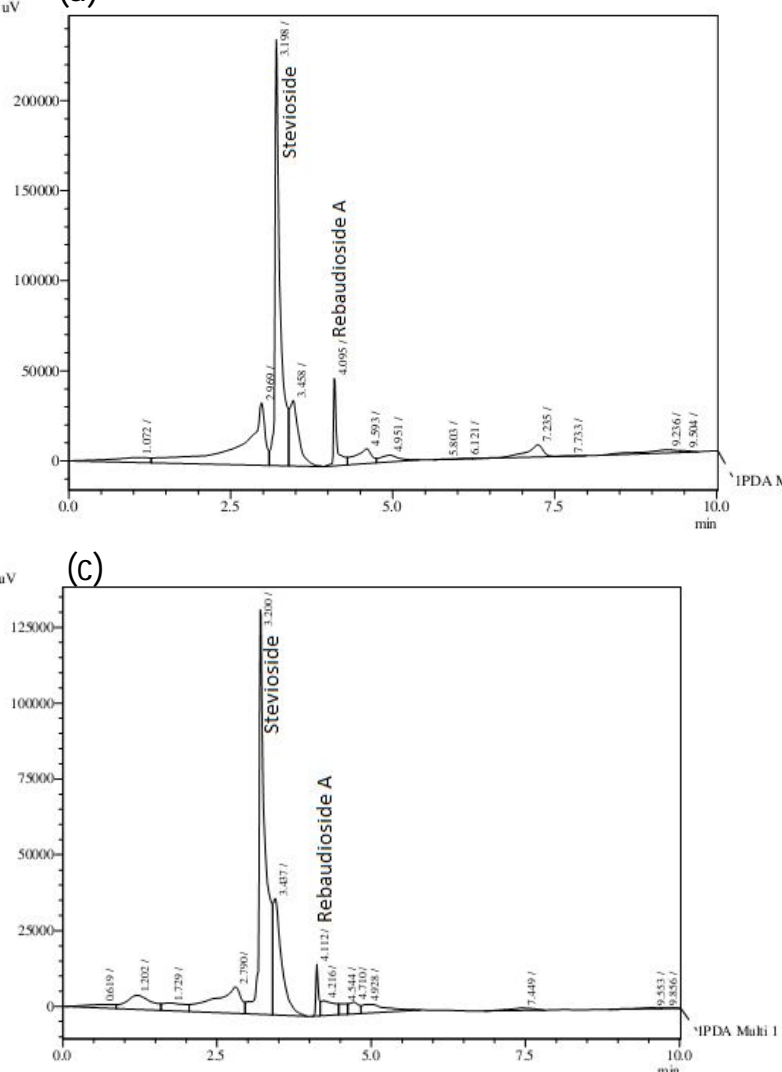

(b)

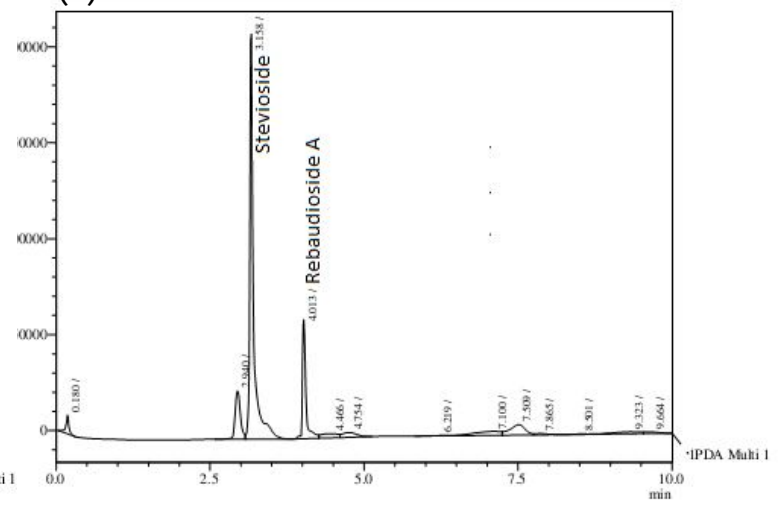

(d)

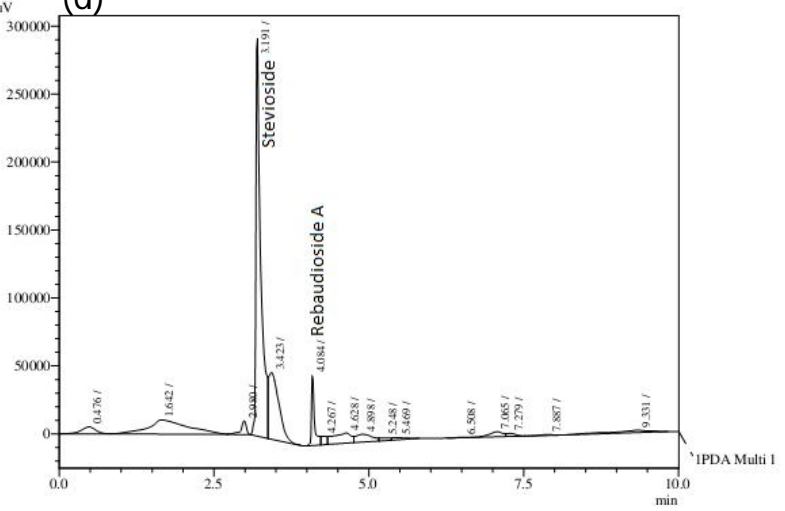

Figure 2: HPLC Chromatogram of stevioside $\left(R_{t}=3.3 \mathrm{~min}\right)$ and rebaudioside $A\left(R_{t}=4.1 \mathrm{~min}\right)$ of sample extract at different material ratio (dried leaves to solvent, w/v) (a) 1:5, (b) 1:10, (c) 1:15, (d) $1: 20$. 


\section{Effect of solvent polarity on the extraction of rebaudioside A}

The total yield and the amount of rebaudioside A extracted using organic solvents, water, and their mixtures are listed in Table 1. The results indicated that high extract yields of rebaudioside A were obtained from extraction employing polar organic solvent containing hydroxyl group, namely methanol, ethanol and aqueous acetone. Low extract yields were observed when the extraction was done using non-polar organic solvent, such as n-hexane and petroleum ether. All extracts obtained from extraction using pure organic solvents were observed as a dark green dry powder. However, extraction using water and aqueous mixed solvents produced powdery extracts with a yellowish-green colour.

The analysis of extracts from $S$. rebaudiana leaves indicated a large yield of rebaudioside A when the extractions were carried out using methanol and ethanol as solvents compared to water (Table 1). Methanol, ethanol, and water have similar solubility properties because they contain a hydroxyl group which is hydrophilic. Rebaudioside A, which is a large and polar hydrocarbon molecule, dissolves better in methanol and ethanol although it has more polar function (Wade, 1987). However, when water was added to methanol or ethanol, the rebaudioside A content in the extract decreased (Table 1). Addition of water into methanol or ethanol will increase their boiling points. The problem with increasing the temperature is that all reactions are accelerated, including all the unwanted side reactions. Among various solvents, absolute methanol shows the largest amount of rebaudioside A extracted but absolute ethanol was selected as a right choice because the extracted rebaudioside A amount were as good as extracted by absolute methanol and it is environmentally benign and relatively safe to human health (Guo-Qing et al., 2005).

Table 1: Effect of polarity of solvent on Extract Yield (EY) of rebaudioside A (g/100g dried leaves) from dried Stevia leaves $\mathrm{ms007}$ and ms012.

\begin{tabular}{|c|c|c|c|}
\hline \multirow{2}{*}{ Solvent } & \multirow{2}{*}{$* \mathrm{PI}^{10}$} & \multicolumn{2}{|c|}{ EY of rebaudioside $A$} \\
\hline & & $\mathrm{ms} 007$ & $\mathrm{~ms} 012$ \\
\hline n-Hexane & 0.1 & 0.007 & - \\
\hline Petroleum Ether & 0.1 & 0.003 & - \\
\hline Acetone $100 \%$ & 5.4 & 1.22 & 1.20 \\
\hline Acetone $70 \%$ & 6.5 & 1.40 & 1.35 \\
\hline Ethanol absolute & 5.2 & 1.81 & 1.72 \\
\hline Ethanol $75 \%$ & 6.2 & 1.53 & 1.46 \\
\hline Ethanol $50 \%$ & 7.1 & 1.20 & 1.11 \\
\hline Methanol absolute & 6.6 & 1.84 & 1.72 \\
\hline Methanol 75\% & 7.2 & 1.70 & 1.59 \\
\hline Methanol 50\% & 7.8 & 1.42 & 1.35 \\
\hline Water & 9.0 & 0.16 & 0.10 \\
\hline
\end{tabular}

*PI = Polarity Index,$(-)=$ no crystals formed 


\section{Effect of temperature on the extraction of rebaudioside $A$}

Figure 3 showed the contents of rebaudioside A which increased gradually with rise in temperature that ranges from $25^{\circ} \mathrm{C}$ to $50^{\circ} \mathrm{C}$ but it started to decrease after $50^{\circ} \mathrm{C}$. It may be due to the greater speed of the molecule movements in higher temperature so that rebaudioside $\mathrm{A}$ diffused more quickly from cell to extracting agent. But the rebaudioside A could be oxidized at temperature surpassing $50^{\circ} \mathrm{C}$ so that the contents of rebaudioside A extracted started to decrease gradually (Yaqin et al., 2005). Temperature effects on extraction are dual. Higher temperature can accelerate the solvent flow and thus increase the rebaudioside A. Higher temperature can also decrease the fluid density that may reduce the extraction efficiency (Guo-Qing et al., 2005). Hence, it was found that $50^{\circ} \mathrm{C}$ was the optimum temperature for extracting the raw rebaudioside A. Temperature also affect the purity of rebaudioside A recovered in the extract. The purity of rebaudioside $\mathrm{A}$ is optimum at $40^{\circ} \mathrm{C}$ but started to decrease as the temperature increases because at higher temperature more unwanted compounds were extracted.

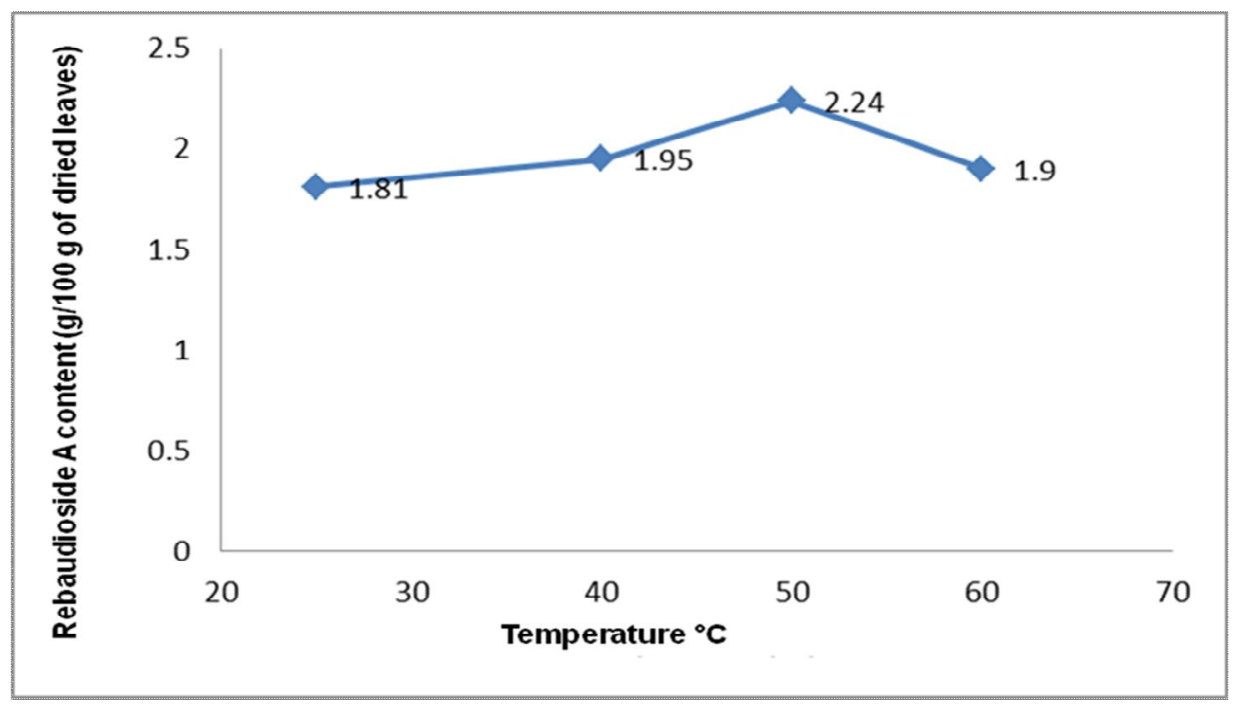

Figure 3: Effect of extraction temperature on rebaudioside A content by absolute ethanol.

\section{Effect of material ratio on the extraction of rebaudioside $A$}

Table 2 shows the contents of rebaudioside A extracted were highest at 1:10 materials ratio compared to $1: 5,1: 15,1: 20$ and 1:25. Further increase in the material ratio leads to a gradual decrease in the rebaudioside A content revealing a saturated condition. A significant drop in the rebaudioside A content was observed with the material ratio of 1:15 to 1:25. This decrease might be due to the fact that when the material ratio reached a certain level, the extract has well dissolved in the solution that may lead the contents of the extract to become saturated and prevent further increase (Yaqin et al., 2005). 
Optimization of Rebaudioside a Extraction from Stevia Rebaudiana (Bertoni) and Quantification by High Perfomance Liquid Chromatography Analysis

Table 1: Effect of Proportion of solvent added to leaves on rebaudioside A content at $\mathbf{T}=50^{\circ} \mathrm{C}$.

\begin{tabular}{ccc}
\hline $\begin{array}{c}\text { Proportion } \\
\text { mass: solvent ratio (w/v) }\end{array}$ & $\begin{array}{c}\text { Rebaudioside A \% } \\
(\mathrm{g} / 100 \mathrm{~g} \text { dried leaves) }\end{array}$ & $\begin{array}{c}\text { Total Soluble Solid } \\
\text { (TSS) } \%\end{array}$ \\
\hline $1: 5$ & 1.53 & 9.0 \\
$1: 10$ & 2.24 & 8.3 \\
$1: 15$ & 2.20 & 8.0 \\
$1: 20$ & 2.05 & 7.2 \\
$1: 25$ & 1.93 & 6.0 \\
\hline
\end{tabular}

\section{Effect of number of extractions on rebaudioside $A$}

The contents of raw rebaudioside A extract increases with the number of extractions i.e., a gradual rise was noticed from 1 time to 4 times. Obviously, when the number of extraction times increased the yield of the respective bioactive principle may also be increased (Chen et al., 2007). In this investigation, the raw rebaudioside A content was not increased after the third extraction, shows in Figure 4. The extraction need to be repeated 3 times in order to recover maximum amount of rebaudioside $\mathrm{A}$.

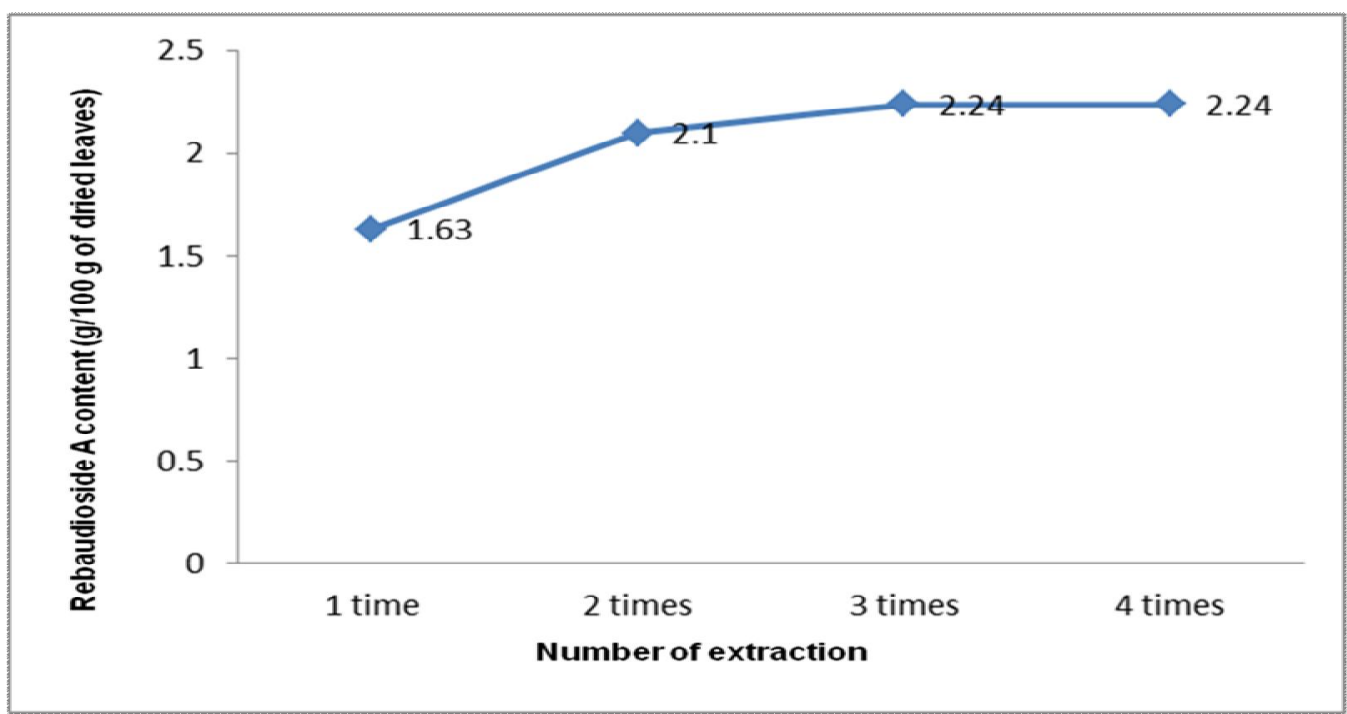

Figure 4: Effect of number of extraction (constant $\mathrm{T}=50^{\circ} \mathrm{C}$ and 1:10 mass: solvent ratio) 


\section{Effect of extraction time on the rebaudioside $A$}

The result of figure 5 shows that the contents of rebaudioside A extracted for 1.5 hours reached maximum and prolonged extraction may not yield an increased content. No further increase in the rebaudioside A content was noticed for 2 hours extract.

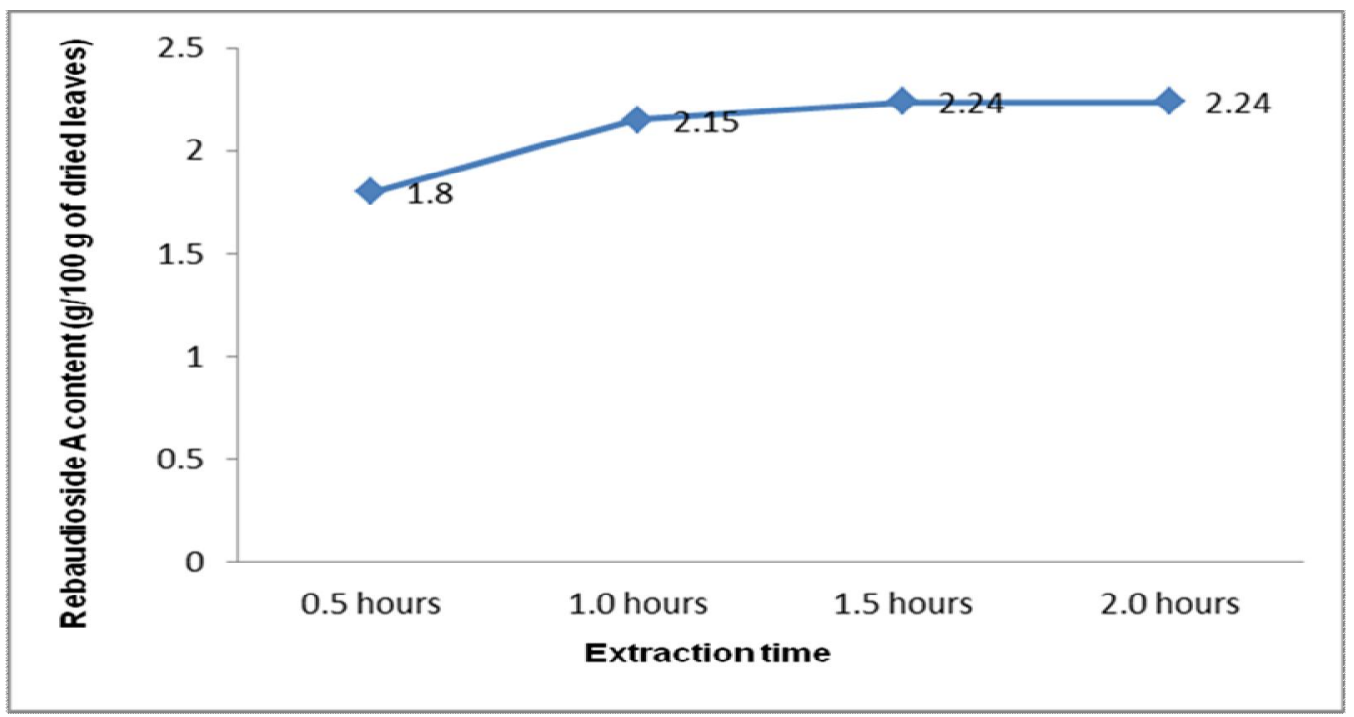

Figure 5: Effect of extraction time in hour. $\left(\mathrm{T}=50^{\circ} \mathrm{C}, 1: 15\right.$ mass of dry leaves powder:solvent ratio and three times extract)

\section{Conclusion}

This study showed that MS007 variety contained more rebaudioside A than MS012. This study also revealed that methanol was the best solvent for the extraction of rebaudioside A from stevia leaves in terms of high extract and component yield. Ethanol and aqueous acetone were also found to be able to extract rebaudioside A, but at a lower yield. The polarity concepts explained the phenomena observed well. Petroleum ether, n-hexane, ethyl acetate, acetone and chloroform might be the best solvents to remove the unwanted components. However, the use of large amounts of unsafe organic solvents may not be a good choice for the processing of high value phytochemicals, especially for the use in the pharmaceutical industry. Further work is being carried out to look into the potential of high-pressure extraction using carbon dioxide and methanol as co-solvent.

\section{Acknowledgments}

This research study was financially supported by the Faculty of Agro Based Industry, Universiti Malaysia Kelantan (UMK), Jeli Campus, Kelantan, Malaysia. The authors would like to thank the Manager of MARDI Station, Bachok, Kelantan for providing the stevia samples. 


\section{References}

Abou-Arab, A. E., Abou-Arab, A. A. and Abu-Salem, M. F. (2010). Physico-chemical assessment of natural sweeteners steviosides produced from Stevia rebaudiana bertoni plant. African Journal of Food Science 4(5): 269- 281.

Barwick, V. J. (1997). Strategies for solvent selection - a literature review. Trends Anal Chem 16: 293-309.

Chen, X. Q., Wu, S. D., Jiang, X. Y. and Chen, Q. Y. (2007). Comparison of Techniques for the Extraction of the Hypotensive Drugs Geniposidic Acid and Geniposide from Eucommia Ulmoides. Journal of Iran. Chemistry Society 4(2): 205-214.

Cramer B, Ikan R. (1987). Progress in the chemistry and properties of rebaudiosides. In: Grenby T.H., editor.Developments in sweeteners New York: Elsevier, 45-48.

Harmanjit, K. (2011). Chromatographic determination of stevioside in leaf parts of in vitro and in vivo regenerated plants of Stevia rebaudiana. International Journal of Natural Products Research 1(4): 2249-2253.

Hu, Z., Liu, H., Wang, K.i, Xu, H., Chen, X. (2002). Application of Experimental Design and Artificial Neural Networks to Separation and Determination of Active Components in Traditional Chinese Medicinal Preparations by Capillary Electrophoresis. Chromatographia. 55: 579-583.

Guo-Qing, H., Hao-Ping, X., Qi-He, C., Ruan, H., Zhao-Yue, W. and Traore, L. (2005). Optimization of conditions for supercritical fluid extraction of flavonoids from hops (Humulus lupulus L.). Journal of Zhejiang University SCI 6B(10): 999-1004.

Jaroslav, P., Barbora, H. and Tuulia, H. (2006). Characteristic of Stevia rebaudiana by comprehensive two-dimensional liquid chromatography time of flight mass spectrometry. J. Chromtagrr. doi. 10.1016/J.Chroma.04050.

Kulasekaran, R., Singh, V. and Megeji, N. W. (2006), Cultivation of Stevia (Stevia rebaudiana): A Comprehensive Review. Advances in Agronomy 89: 137-177.

Wade, Jr., L. G. (1987) Organic Chemistry, Prentice-Hall, New York, 23-35.

Leung, A. Y. and Foster, S. (1996). Encyclopedia of common natural ingredients $Đ$ used in food, drugs and cosmetics ( $2^{\text {nd }}$ ed.). New York: John Wiley and Sons, Inc. 2, 478.

Lewis, W. H. (1992). Early uses of Stevia rebaudiana (Asteraceae) leaves as a sweetener in Paraguay. Econ. Bot. 46: 336-337.

Midmore, D. J. and Rank, A. H. (2002). A new rural industry- Stevia to replace imported chemical sweeteners, RIRDC web publication, Project No. UCQ-16A.

Raji, A. A. and Mohamad, O. (2011). Effects of stem cutting types, position and hormonal factors on rooting in Stevia rebaudiana Bertoni, Journal of Agricultural Science 4(1): 4957.

Richard, D. (2006). Stevia rebaudiana Nature's Sweet Secret. Vital Health Publishing, 9-15.

Soejarto, D. D., Compadre, C. M., Medon, P. J., Kamath, S. K. and Kinghorn, A. D.

(1983). Potential sweetening agents of plant origin. II. Field search for sweet-tasting Stevia species. Economic Botany 37(1): 71-79.

Yaqin, X., Rui, Z. and Hong, F. (2005). Studies on the optimal process to extract flavonoids from red-raspberry fruits. Nature and Science 3(2): 43-46. 